J. Lake Sci. (湖泊科学), 2011, 23(6): 888-892

http: //www.jlakes.org. E-mail: jlakes@niglas. ac.cn

(c) 2011 by Journal of Lake Sciences

\title{
华南坡地单场降雨氮素的迁移特征及来源分析”
}

\author{
黎 坤 $^{1,2}$, 江 涛 $^{1,2}$, 卓慕宁 ${ }^{3}$, 陈建耀 ${ }^{1,2}$, 刘春玲 ${ }^{4}$ \\ (1: 中山大学水资源与环境研究中心,广州 510275) \\ (2: 华南地区水循环与水安全广东省普通高校重点实验室,广州 510275) \\ (3: 广东省生态环境与土壤研究所,广州 510650) \\ (4: 水利部珠江水利委员会珠江水利科学研究院,广州 510611)
}

\begin{abstract}
摘 要: 通过两个径流场的对比试验, 研究了华南坡地氮素在某场降雨下的迁移特征和来源, 结果表明, 在没有施肥的情 况下, 氮素的迁移形态以铵氮、硝氮为主, 总氮、硝氮和亚硝氮的迁移以地下下渗迁移为主, 铵氮的迁移以地表迁移为主; 在施放尿素的情况下, 氮素的迁移形态以溶解态的尿素、铵氮和硝氮为主, 总氮、溶解态尿素和铵氮的迁移以地表径流迁 移为主, 硝氮、亚硝氮、有机氮的迁移以地下下渗迁移为主. 在天然情况下, 降雨带来的氮沉降已经成为试验坡地氮素迁 移的主要来源之一.
\end{abstract}

关键词: 氮素;迁移特征;氮沉降; 来源

\section{Transportation and sources of nitrogen in a single rainfall event in the hillsides of South China}

LI Kun ${ }^{1,2}$, JIANG Tao ${ }^{1,2}$, ZHUO Muning ${ }^{3}$, CHEN Jianyao ${ }^{1,2} \&$ LIU Chunling ${ }^{4}$

(1: Department of Water Resources and Environment, Sun Yat-sen University, Guangzhou 510275, P. R. China)

(2: Key Laboratory of Water Cycle and Water Security in Southern China of Guangdong High Education Institute, Sun Yat-sen University, Guangzhou 510275, P. R. China)

(3: Guangdong Institute of Eco-environment and Soil Sciences, Guangzhou 510650, P. R. China)

(4: Pearl River Hydraulic Research Institute, Guangzhou 510611, P. R. China)

\begin{abstract}
Comparisons have been done on the experiments about the transportation and sources of nitrogen in the hillsides within a single rainfall event in south China. Results indicate that the release of the nitrogen is represented by ammonia nitrogen and nitrate nitrogen. Transportation of the total nitrogen, nitrate nitrogen and nitrous nitrogen is dominated by infiltration process, and that of the ammonia nitrogen is dominated by the surface migration. In the case of the urea release, the migration of the nitrogen is dominated by the dissolved form of urea, ammonia nitrogen and nitrate nitrogen. The total nitrogen, dissolved urea and ammonia nitrogen is characterized by the surface migration. The transportation of the nitrate nitrogen, nitrous nitrogen and organic nitrogen is dominated by the underground infiltration process. Without human interference, rainfall-induced nitrogen deposition has become one of the main sources of the nitrogen in the experiment field.
\end{abstract}

Keywords: Nitrogen; transportation properties; nitrogen deposition; sources

氮等养分随地表径流向水体的迁移引起了广泛的重视 ${ }^{[1]}$, 氮肥施用量的多少是决定氮素迁移量的最主 要因素 ${ }^{[2]}$, 研究表明氮的迁移量与施氮量呈显著的线性正相关 ${ }^{[3]}$, 同时, 氮素的迁移还受肥料种类、施肥时 间、施肥方式等的影响. 在氮的迁移流失来源中, 大气氮沉降是其中一个主要来源, 有研究表明, 中北美、西 欧和亚洲的中国、印度已经成为全球氮沉降的三大集中分布区 ${ }^{[4]}$. 据估计, 全球每年沉降到陆地生态系统的 活性氮达 $43.47 \mathrm{Tg}^{[5]}$. 湿沉降向土壤输人的硝氮和铵氮是补偿农田生态系统氮素损失的重要途径之一 ${ }^{[6]}$. 同

* 国家自然科学基金项目 (41071020) 和广东省水利科技推广项目 (2009) 联合资助. $2011-02-18$ 收稿; $2011-05-$ 04 收修改稿. 黎坤,男,1969 年生,博士,工程师; E-mail: eeslk@ mail. sysu. edu. cn. 
时氮养分迁出土壤系统进人水体成为水体富营养化的非点源污染源, 因此研究降雨径流中的土壤氮素随径 流的迁移特征及来源对协调农林业生产与水环境保护问题具有重要意义 ${ }^{[7]}$.

研究降雨径流条件下土壤氮等养分的迁移特征, 可以利用人工模拟降雨及野外观测等手段, 我国这方 面的研究是从黄土高原结合水土流失 ${ }^{[8-11]}$ 开始的, 主要以农田系统养分的迁移规律研究为主 ${ }^{[12-15]}$, 在野外 自然降雨的情况下对山林坡地氮迁移规律研究不多, 为此本文通过华南湿润区滨海野外径流实验场某场降 雨的氮素迁移的同步采样观测, 对华南湿润区滨海山林坡地在降雨径流中氮的迁移特征及来源进行研究, 为有效控制农林业氮素的损失和防止水体的富营养化提供科学依据.

\section{1 试验场地}

本次研究选择了中山大学珠海校区龙潭流域的野外两个径流试验场地. 两个径流试验场是 $5 \mathrm{~m} \times 10 \mathrm{~m}$ 的长方形实验场地,场地四周边界往下开挖到基岩, 并用水泥砖浆砌, 阻断了实验场地内水流向四周边界外 漫流, 形成一个相对封闭的实验场地. 实验场地坡度约为 $20^{\circ}$, 在下坡边界, 建设有水流收集槽, 通过管道将 水流引人储水罐中收集. $\mathrm{A}$ 号场地表土覆盖深度约为 $2.8 \mathrm{~m}$, 设有储水罐分别收集坡面表层、土壤中层(约深 $1.5 \mathrm{~m}$ ) 和土壤底层 (基岩底部) 三层水流. $\mathrm{B}$ 号场地由于表土覆盖较浅, 平均表土覆盖深度约 $0.8 \mathrm{~m}$, 水流收 集槽分表层和底层 (基岩底部) 两层收集水流, $\mathrm{A}$ 号场和 $\mathrm{B}$ 号场相隔 $50 \mathrm{~m}$ 左右, 径流场土壤类型为黄色沙壤 土, 植被为低矮针叶松.

为了揭示华南湿润地区山林坡地上氮素的迁移特征及其来源, 本研究设计了一个观测实验, 利用现有 的两个径流实验场, 即两个相对封闭坡地, 在下雨前对其中一个径流场 A 施放尿素, 同时记录施肥的数量和 施肥时间, 而另一个径流场 B 保持现状, 在自然降雨开始时, 在两个径流场汇水口即刻采样, 同时在径流场 旁放置雨水收集器, 采集整个降雨过程的雨水. 通过径流场旁的数字雨量计对降雨过程进行观测, 记录降雨 过程, 通过储水罐水位计记录出流过程.

水样分析项目为: 总氮、铵氮、硝氮、亚硝氮等.

\section{2 野外试验}

按照试验设计,在预报有雨情况下于 2009 年 3 月 24 日 11 时, 对径流场 A 施放了 $2.5 \mathrm{~kg}$ 尿素, 均匀撒 在了 $\mathrm{A}$ 径流场表层土壤上面, 于 3 月 25 日 $11: 00$ 时录得伴随小许产流的小雨一场 (降雨量 $6.6 \mathrm{~mm}$, 历时 $45 \mathrm{~min}$ ) ; 之后, 于 3 月 27 日又录得了第二场雨 (中雨), 降雨量为 $34.2 \mathrm{~mm}$, 并伴随了较大产流.

按照实验设计, 对两场降雨的氮产出过程进行监测. 在降雨开始时, 在两个径流场 A、B 汇水口即刻采 样,每间隔 $15 \mathrm{~min}$ 采样一次, 直至无明显产流为止.

由于实验坡面植被覆盖完好, 并且坡地还覆盖有一层针叶松落叶, 一般的降雨产流中, 径流里含沙量稀 少, 径流收集桶底部几乎没有沉沙, 径流收集桶中的水也是很清澈的, 对径流场近两年的观测, 中小雨下径 流场里产流中含沙量稀少, 所以本次研究没有测量坡面产流中的含沙量. 由于中小雨下径流场里产流中含 沙量稀少, 因此认为在中小雨情况下, 这两径流场中的营养物流失主要以淋洗态流失为主, 悬浮态流失所占 比重很小, 这是本次研究中没有测量颗粒态氮的原因.

\section{3 试验结果分析}

\section{1 降雨产流过程}

本次试验在施放化肥 (尿素) 约 $72 \mathrm{~h}$ 后,采集到 了两场降雨,但第一场降雨由于雨量较小, 产流不明 显,故本次研究只论述第二场降雨的情况. 第二场降 雨总雨量 $34.2 \mathrm{~mm}$, 降雨历时 5 小时 30 分钟,但是形 成产流过程只有 $75 \mathrm{~min}$, 从其降雨产流过程 (图 1) 可 以看出, 由于试验坡地空间尺度较小, 产流开始后, 产 流流量与降雨强度关联很大, 降雨强度越大, 产流流 量也越大.

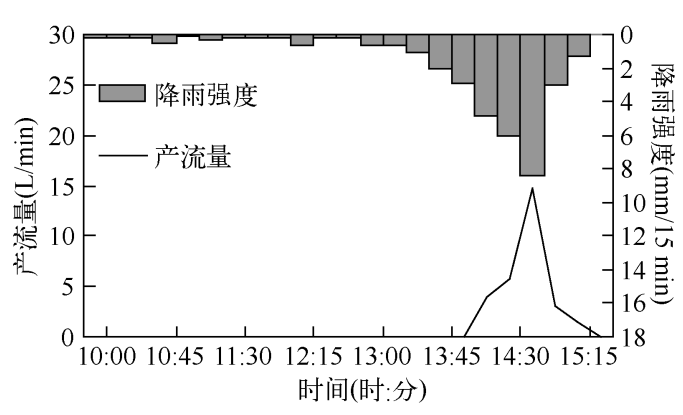

图 1 降雨产流过程

Fig. 1 Runoff generation process during a rainfall event 


\section{2 氮迁移形态与比例}

本次试验对地表降雨径流过程进行了测量, 并收集了地表径流全部产流, 由于地下基岩存在裂隙, 所以本次试验只收集到了部分地下径流, 其地下下渗总水量用净雨量减去地表径流量得到, 以各收集 桶的水样浓度作为对应的地表产流或地下下渗的氮平均浓度. 根据采样分析结果和对应的地表产流 量和下渗量,可以计算出实验坡地氮素迁移量、迁移形态和比例.

从该场降雨中 A 径流场的氮素的迁移形态主要是溶解态的尿素、铵氮和硝氮三种形态, 三者的比例分 别为 $28.99 \% 、 37.58 \% 、 28.14 \%$, 亚硝氮和有机氮所占比例较小, 分别为 $2.16 \%$ 和 $3.12 \%$ (图 2).

对于没有施肥的 B 径流场, 氮素的迁移以铵氮和硝氮形态为主, 所占比例分别为 $42.10 \%$ 和 $46.36 \%$, 有 机氮、亚硝氮形态流失的比例较低,分别为 $9.93 \%$ 和 $1.61 \%$ (图 3).

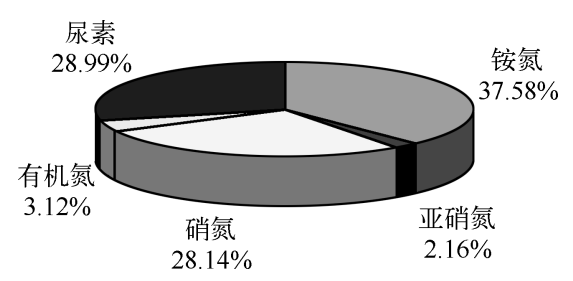

图 2 某场降雨 $\mathrm{A}$ 径流场氮迁移形态和比例

Fig. 2 States and percentages of the nitrogen migration in a rainfall event after fertilization

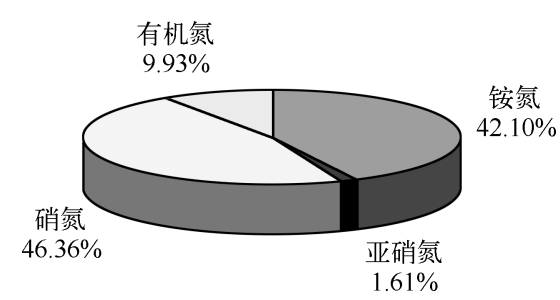

图 3 某场降雨 $\mathrm{B}$ 径流场氮迁移形态和比例

Fig. 3 States and percentages of the nitrogen migration in a rainfall event without human interference

土壤中的氮以及人工施人土壤的肥料氮在降雨的作用下, 部分直接以化合物形式 (如尿素), 而大部分 最终以可溶性的 $\mathrm{NO}_{3}^{-} 、 \mathrm{NO}_{2}^{-}$和 $\mathrm{NH}_{4}^{+}$形式渗漏淋失到雨水及土壤下层. 该迁移过程伴随着化学转化反应, 如 矿化 (有机质 $\rightarrow \mathrm{NH}_{4}^{+}$) 、水解 (尿素: $\left(\mathrm{NH}_{2}\right)_{2} \mathrm{CO}+\mathrm{H}_{2} \mathrm{O} \rightarrow \mathrm{CO}_{2}+\mathrm{NH}_{3} \rightarrow \mathrm{NH}_{4}^{+}$)、氨挥发 $\left(\mathrm{NH}_{4}^{+}+\mathrm{OH}^{-} \rightarrow \mathrm{NH}_{3}\right.$ ), 硝 化 $\left(\mathrm{NH}_{4}^{+} \rightarrow \mathrm{NO}_{3}^{-}\right)$、反硝化 $\left(\mathrm{NO}_{3}^{-} \rightarrow \mathrm{NO}_{2}^{-} \rightarrow \mathrm{N}_{2} \mathrm{O} \rightarrow \mathrm{N}_{2}\right)$ 、土壤固定 $\left(\mathrm{NH}_{4}^{+}\right)$以及作物吸收. 因此坡地土壤氮迁移 主要形态为 $\mathrm{NO}_{3}^{-}$和 $\mathrm{NH}_{4}^{+}$, 尿素施放的初期也含大量溶解态尿素.

\section{3 氮素的地表迁移和地下迁移}

$\mathrm{A}$ 径流场中的溶解态尿素和铵氮的迁移以地表径流迁移为主, 主要原因是施肥后, 尿素颗粒在雨滴的 冲击下破碎然后淋溶进人地表径流, 同时尿素施放到地表后在雨水作用下水解, 先转化为铵氮, 所以铵氮随 地表径流的迁移比例比较高. 总氮的迁移也以地表径流迁移为主, 主要是受溶解态尿素和铵氮在地表的迁 移比例较高的影响, 硝氮的迁移以地下下渗迁移为主, 占 $68.2 \%$, 亚硝氮的迁移以地下下渗迁移为主, 占 $96.7 \%$, 有机氮的地表径流迁移量占 $41.2 \%$, 地下下渗迁移量占 $58.8 \%$, 下渗迁移比例比地表迁移比例大一 些,亚硝氮和有机氮在总氮中所占比例非常小 (表 1 , 表 2 ).

表 1 某场降雨 $A 、 B$ 两径流场不同层次氮素迁移量 $(\mathrm{g})$

Tab. 1 Migration quantity of the nitrogen within different soil layers of A and B proving ground during a rainfall event

\begin{tabular}{cccccccc}
\hline 径流场 & 层次 & 铵氮 & 硝氮 & 亚硝氮 & 有机氮 & 尿素 & 总氮 \\
\hline \multirow{2}{*}{$\mathrm{A}$} & 地表 & 5.640 & 2.021 & 0.016 & 0.290 & 5.593 & 13.560 \\
& 地下 & 2.846 & 4.334 & 0.472 & 0.415 & 0.953 & 9.020 \\
& 小计 & 8.486 & 6.354 & 0.488 & 0.705 & 6.546 & 22.580 \\
\hline \multirow{2}{*}{$\mathrm{B}$} & 地表 & 1.562 & 1.248 & 0.018 & 0.280 & 0 & 3.108 \\
& 地下 & 1.430 & 2.046 & 0.097 & 0.395 & 0 & 3.968 \\
& 小计 & 2.992 & 3.295 & 0.114 & 0.675 & 0 & 7.076 \\
\hline
\end{tabular}


表 2 氮素随地表径流和地下下渗的迁移比例 (\%)

Tab. 2 Percentages of the nitrogen transported with surface runoff and ground runoff

\begin{tabular}{cccccccc}
\hline 径流场 & 层次 & 铵氮 & 硝氮 & 亚硝氮 & 有机氮 & 尿素 & 总氮 \\
\hline \multirow{2}{*}{ A } & 地表 & 66.5 & 31.8 & 3.3 & 41.2 & 85.4 & 60.1 \\
& 地下 & 33.5 & 68.2 & 96.7 & 58.8 & 14.6 & 39.9 \\
\hline \multirow{2}{*}{ B } & 地表 & 52.2 & 37.9 & 15.5 & 41.5 & 0 & 44.0 \\
& 地下 & 47.8 & 62.1 & 84.5 & 58.5 & 0 & 56.0 \\
\hline
\end{tabular}

$\mathrm{B}$ 径流场中土壤是纯天然状态, 由于没有施肥影响, 所以不存在溶解态尿素的迁移. 总氮的迁移中地下 下渗迁移所占比例较大, 占 $56.1 \%$; 而铵氮的迁移中, 地表迁移与地下下渗迁移的比例大体相当; 硝氮的迁 移以地下下渗迁移为主, 占 $62.1 \%$; 亚硝氮的迁移以地下下渗迁移为主, 占 $84.5 \%$.

一般情况下土壤胶体都带负电,带正电荷的 $\mathrm{NH}_{4}^{+}$易被带负电荷的土壤胶体所吸附, 所以铵氮较少沿土 壤剖面垂直向下移动或从土壤中渗漏淋失,基本滞留在土壤剖面上、中层, 而带负电荷的 $\mathrm{NO}_{3}^{-}$不被土壤胶体 所吸附, 可以随水自由移动, 极易淋洗到下层.

\section{4 氮素迁移来源辨析}

A 径流场氮素的迁移主要来源于三个方面:施肥后肥料养分的流失、土壤本身固有的营养物随径流的 流失和大气沉降. B 径流场氮素的迁移主要来源于两个方面:土壤本身固有的营养物随径流的流失和大气 沉降. 本次试验采集了该场降雨的雨水,其中铵氮、亚硝氮、硝氮和总氮的平均浓度分别为 $1.06 、 0.016 、 0.95$ 和 $2.25 \mathrm{mg} / \mathrm{L}$. 假设降雨过程中, 在氮素迁移时各种形态氮素在短时间内没有发生相互转化, 同时由于 B 径 流场没有施用化肥, A、B 两径流场面积一样,表土大体一致, 可以近似认为, 如果 A 径流场也没有施用化肥 的话, 本次降雨过程各种氮素的流失量应该与 $\mathrm{B}$ 径流场大体一致. 在此基础上,根据物料平衡原理,可以计 算出氮素迁移的来源.

某场降雨中, $\mathrm{A}$ 径流场由于施肥的原因,氮素迁移的主要来源是尿素的施放. 总氮迁移量的 $68.5 \%$ 来源 于肥料施放, $14.7 \%$ 来源于土壤养分的流失, $16.8 \%$ 来源于降雨带来的氮沉降; 铵氮迁移量的 $64.7 \%$ 来源于 肥料施放, $14.3 \%$ 来源于土壤养分的流失, $21.0 \%$ 来源于降雨带来的氮沉降; 硝氮迁移量的 $48.2 \%$ 来源于肥 料施放, $26.6 \%$ 来源于土壤养分的流失, $25.2 \%$ 来源于降雨带来的氮沉降; 溶解态尿素迁移量 $100 \%$ 来源于 肥料的施放 ( 图 4 ).
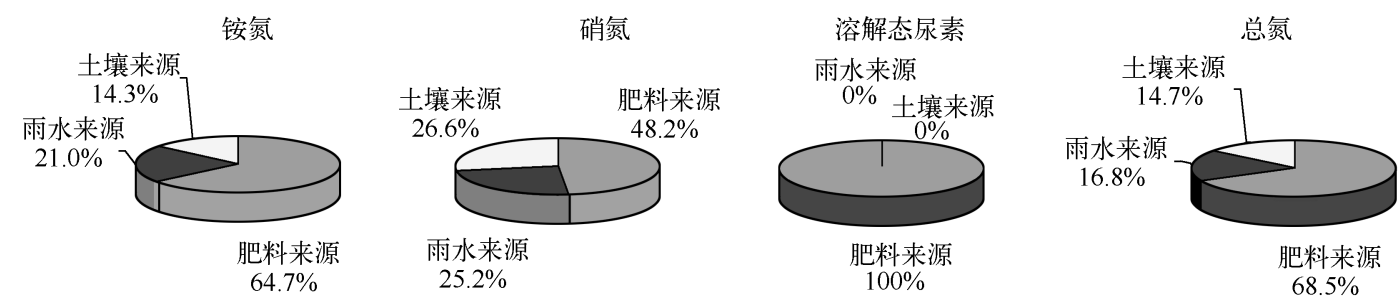

图 $4 \mathrm{~A}$ 径流场施肥后氮素迁移来源

Fig. 4 Sources of the nitrogen after the fertilization

$\mathrm{B}$ 径流场, 由于没有施肥, 氮素的迁移主要来源于降雨带来的氮沉降和土壤养分的流失. 总氮的迁移量 中 $46.6 \%$ 来源于土壤养分的流失, $53.4 \%$ 来源于雨水带来的氮沉降; 铵氮的迁移量中 $40.4 \%$ 来源于土壤养分 的流失, $59.6 \%$ 来源于雨水带来的氮沉降; 硝氮的迁移量中 $51.4 \%$ 来源于土壤养分的流失, $48.6 \%$ 来源于雨水 带来的氮沉降, 在没有施肥情况下, 雨水带来的氮沉降成了径流场中氮素迁移的主要来源之一(图 5).

\section{4 结论}

（1）在天然情况下 (没有施肥), 试验径流场氮的迁移形态以铵氮、硝氮为主,在施放尿素的情况下, 试验 

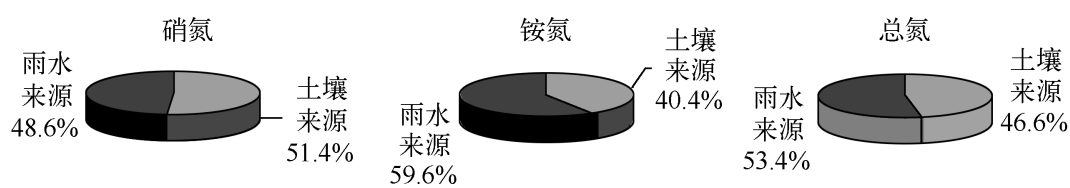

图 5 B 径流场天然情况下氮素迁移来源

Fig. 5 Source of the nitrogen in the condition without human interference

径流场氮素随径流的迁移形态以溶解态的尿素、铵氮和硝氮为主; 亚硝氮和有机氮在总氮中所占比例很小.

(2) 在施放尿素的情况下, 试验径流场总氮、溶解态尿素和铵氮的迁移以地表径流迁移为主, 硝氮、亚 硝氮、有机氮的迁移以地下下渗迁移为主.

（3）在天然情况下, 试验径流场总氮、硝氮和亚硝氮的迁移以地下下渗迁移为主. 铵氮的迁移中, 地表 迁移与地下下渗迁移的比例大体相当.

(4) 在施放尿素的情况下, 试验径流场氮素迁移的主要来源是尿素的施放. 总氮迁移量的 $68.5 \%$ 来源 于肥料施放, $14.7 \%$ 来源于土壤养分的流失, $16.8 \%$ 来源于降雨带来的氮沉降; 铵氮迁移量的 $64.7 \%$ 来源于 肥料施放, $14.3 \%$ 来源于土壤养分的流失, $21.0 \%$ 来源于降雨带来的氮沉降; 硝氮迁移量的 $48.2 \%$ 来源于肥 料施放, $26.6 \%$ 来源于土壤养分的流失, $25.2 \%$ 来源于降雨带来的氮沉降; 溶解态尿素迁移量 $100 \%$ 来源于 肥料的施放.

(5) 在天然情况下, 试验径流场氮素的迁移主要来源于降雨带来的氮沉降和土壤养分的流失. 总氮的迁 移量中 $46.6 \%$ 来源于土壤养分的流失, $53.4 \%$ 来源于雨水带来的氮沉降; 铵氮的迁移量中 $40.4 \%$ 来源于土壤 养分的流失, $59.6 \%$ 来源于雨水带来的氮沉降; 硝氮的迁移量中 $51.4 \%$ 来源于土壤养分的流失, $48.6 \%$ 来源于 雨水带来的氮沉降; 在天然情况下, 雨水带来的氮沉降成了试验径流场中氮素迁移的主要来源之一.

\section{5 参考文献}

[1 ] 窦培谦, 王晓燕, 王丽华. 非点源污染中氮磷迁移转化机理研究进展. 首都师范大学学报 (自然科学版), 2006, $27(2)$ : 93-98.

[ 2 ] Aronsson PG. Dynamics of nitrate leaching and ${ }^{15} \mathrm{~N}$ turnover in intensively fertilized and irrigated basket willow grown in lysimeters. Biomass and Bioenergy, 2001, 21(3) : 143-154.

[ 3 ] 金 洁, 杨京平. 高肥力稻田分次施氮对氮素淋失的影响. 水土保持学报, 2004, 18(3): 98-101.

[4] Twonsend AR, Braswell BH, Holland EA et al. Spatial and temporal patterns in terrestrial carbonstorage due to deposition of fossil fuel nitrogen. Ecological Applications, 1996, 6: 804-814.

[ 5 ] Holland EA, Dentene FJR, Braswell BH et al. Contemporary and pre-industrial global reactivenitrogen budgets. Biogeochemistry, $1999, \mathbf{4 6}: 7-43$.

[ 6 ] Haynes RJ. Origin, Distribution and cycling of nitrogen in terrestrial ecosystems. In: Hanynes RJ, ed. Mineral nitrogen in plant-soil system. Orlando: Academic Press, 1986: 1-51.

[7] 许 峰, 蔡强国, 吴淑安. 坡地农林复合系统养分过程研究进展. 水土保持学报, 2000, 14(1): 83-87.

[8] 王 辉, 王全九, 邵明安. 人工降雨条件下黄土坡面养分随径流迁移试验. 农业工程学报, 2006, 22(6) : 39-44.

[9] 李艳梅, 袁 霞, 张亚丽等. 黄绵土坡面土壤矿质氮素径流流失与人渗特征研究. 农业环境科学学报, 2007 , 26(1) : 246-251.

[10] 王 超. 氮类污染物在土壤中迁移转化规律试验研究. 水科学研究进展, 1997, 8(2):176-181.

[11] 张兴昌, 张亚丽. 径流与坡面土壤矿质氮素的作用深度研究. 科学技术与工程, 2005, 5 (17): 1256-1259.

[12] Ramos MC, Martínez-Casasnovas JA. Nutrient losses by runoff in vineyards of the Mediterranean Alt Penedès region( NE Spain). Agriculture Ecosystems and Environment, 2006, 113 (1-4) : 356-363.

[13] 黄满湘, 章 申, 唐以剑等. 模拟降雨条件下农田径流中氮的流失过程. 土壤与环境, 2001, 10(1):6-10.

[14] 袁冬海, 王兆塞, 陈 欣等. 不同农作方式红壤坡耕地土壤氮素流失特征. 应用生态学报, $2002, \mathbf{1 3}$ ( 7 ): $863-866$.

[15] 尹 娟, 王南江, 勉韶平. 稻田土壤中氮素运移转化规律的试验研究. 灌溉排水学报 2005, 24(3): 5-7. 